\title{
Corrigendum: High-performance n-type black phosphorus transistors with type control via thickness and contact-metal engineering
}

David J. Perello, Sang Hoon Chae, Seunghyun Song \& Young Hee Lee

Nature Communications 6:7809 doi: 10.1038/ncomms8809 (2015); Published 30 Jul 2015; Updated 28 Jan 2016

In Fig. 3 of this article, there are a number of errors in the colours used for the data points and curves. In Fig. $3 b$, the blue data should be green, referring to a thickness of ' $3.5 \mathrm{~nm}$ ', and the green data should be blue, referring to a thickness of ' $8 \mathrm{~nm}$ '. In Fig. $3 \mathrm{~d}$, the blue data should be green and refer to a thickness of ' $3.5 \mathrm{~nm}$ ', the green data should be blue and refer to a thickness of ' $8 \mathrm{~nm}$ ' and the orange data should refer to a thickness of ' $13 \mathrm{~nm}$ '.

In Table 1, the Pd contacts on 13-14.5 nm of BP were 'Unipolar p-type', not 'Unipolar n-type'.

The correct version of Fig. 3 and Table 1 appear below.

a

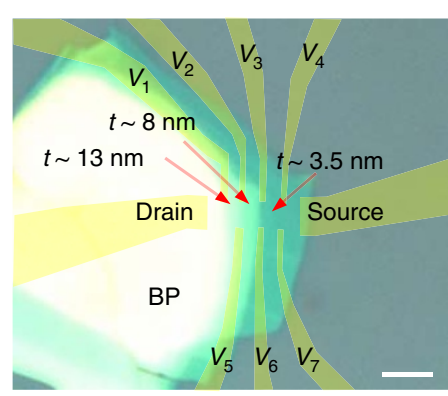

C

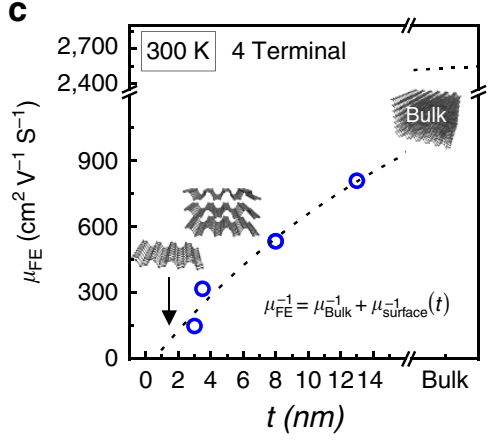

b

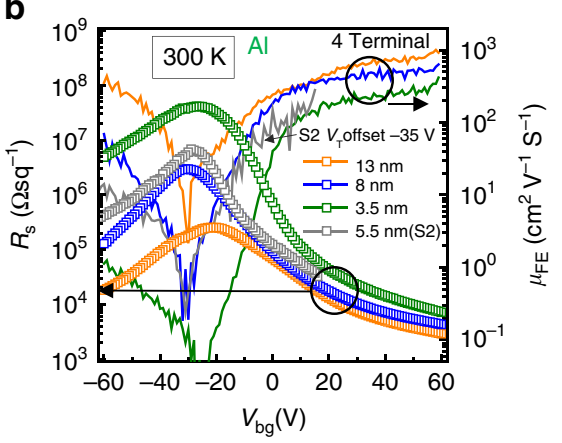

d

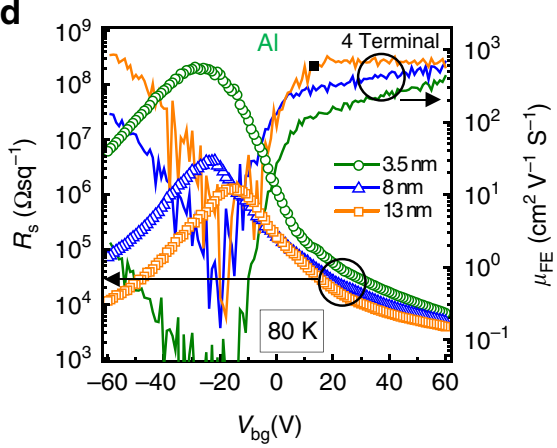

Figure 3 


\section{Table 1 | Type control summary by thickness and contact metal.}

\begin{tabular}{|cccc|} 
& \multicolumn{3}{c}{ BP thickness } \\
\cline { 2 - 4 } & $\mathbf{2 . 5 - 5 . 5} \mathbf{~ n m}$ & $\mathbf{7 - 8} \mathbf{~ n m}$ & $\mathbf{1 3 - 1 4 . 5} \mathbf{~ n m}$ \\
\hline Al contacts & $\begin{array}{c}\text { Unipolar n-type } \\
\text { Ambipolar }\end{array}$ & $\begin{array}{c}\text { Unipolar } \mathrm{n} \text {-type } \\
\text { Ambipolar } \text { p-type dominant }\end{array}$ & $\begin{array}{c}\text { Ambipolar } \\
\text { Unipolar } \text {-type }\end{array}$ \\
\hline
\end{tabular}

(c) (i) This work is licensed under a Creative Commons Attribution 4.0 International License. The images or other third party material in this article are included in the article's Creative Commons license, unless indicated otherwise in the credit line; if the material is not included under the Creative Commons license, users will need to obtain permission from the license holder to reproduce the material. To view a copy of this license, visit http://creativecommons.org/licenses/by/4.0/ 